\title{
Tool Use of Experienced Learners in Computer-Based Learning Environments: Can Tools Be Beneficial?
}

\author{
Norma A. Juarez Collazo ${ }^{1}$, David Corradi ${ }^{1}$, Jan Elen ${ }^{1} \&$ Geraldine Clarebout ${ }^{2}$ \\ ${ }^{1}$ Center of Instructional Psychology and Technology, KU Leuven, Belgium \\ ${ }^{2}$ Interdisciplinary Research team on Technology, Education and Communication—IBBT, KU Leuven—kulak, \\ Belgium \\ Correspondence: Norma A. Juarez Collazo, Center of Instructional Psychology and Technology, KU Leuven, \\ Dekenstraat 2, Box 3773, Leuven, Belgium. Tel: 32-162-6205. E-mail: norma.juarez@ppw.kuleuven.be
}

Received: October 25, 2013 Accepted: December 13, 2013 Online Published: January 23, 2014

doi:10.5539/hes.v4n1p26 URL: http://dx.doi.org/10.5539/hes.v4n1p26

\begin{abstract}
Research has documented the use of tools in computer-based learning environments as problematic, that is, learners do not use the tools and when they do, they tend to do it suboptimally. This study attempts to disentangle cause and effect of this suboptimal tool use for experienced learners. More specifically, learner variables (metacognitive and motivational) were related to the tool presentation (non-/embedded), interventions, type of tool use (quantitatively and qualitative) and learners' performance. One hundred and seventeen graduate students were assigned to one of five conditions (embedded and non-embedded with explained tool functionality, embedded and non-embedded with non-explained tool functionality and one control condition) to study a hypertext using semi-structured concept maps as the tools. Findings are discussed with respect to experienced learners' role on tool use and performance. Although no differences among conditions and performance were found, results reveal that the self-regulation skill of organization and the explained tool functionality affected time on tool negatively, while the self-regulation skill of elaboration and perceived tool usability showed a positive effect. Time on tool influenced performance positively. Quality influenced performance negatively. It is argued that some tools and interventions are unnecessary for experienced learners.
\end{abstract}

Keywords: computer-based learning environments, goal orientation, self-efficacy, semi-structured concept maps, tool interventions, tools presentation, experienced learners, learning outcomes

\section{Introduction}

Learners are often offered an array of different (learning) tools in computer-based learning environments (CBLEs). These CBLEs often assume learners are good judges of their learning needs and will therefore use the offered tools according to the tools' main aim, which is to help the learners learn better (Aleven, Stahl, Schworm, Fischer, \& Wallace, 2003). However, research has indicated that the use of tools is problematic: The presence of tools does not guarantee that tools will be used and if tools happen to be used, this usage does not guarantee effective tool use (Elen \& Clark, 2006). In this regard, research has already documented that learners tend to avoid the use of tools (Aleven et al., 2003; Perkins, 1985) and when they decide to use the tools, learners tend to use them inadequately (Aleven et al., 2003; Perkins, 1985).

The use of tools has been classified as either quantitative or qualitative. While quantity of tool use focuses on amount of tool use (e.g., time spent on tool and frequency of tool use) (Clarebout, Horz, Schnotz, \& Elen, 2010; Viau \& Larivée, 1993), quality of tool use tries to analyze how learners include the tools in their learning process (Jiang \& Elen, 2011; Zumbach, 2009). The purpose of research exploring different ways of tool usage in CBLEs is to analyze the effects tool use may have on learning outcomes (i.e., performance) (Aleven et al., 2003; Clarebout \& Elen, 2006).

The question remains whether these claims are generalizable for experienced learners, who have already gone through a number of years of advanced higher education and for whom CBLEs are often made for (Lust, Juarez Collazo, Elen, \& Clarebout, 2012). According to Aleven et al. (2003), tool use improves with age, which is directly related to learners' improvement of metacognitive and motivational variables (see also: Perkins, 1985). Moreover, the different characteristics of the tool itself (Perkins, 1985) may impact the (mis)use of tools in 
addition to the influence (instructional) interventions may also have. Therefore, it is questionable whether experienced learners need tools. Moreover, if tools are used, it is also questioned how tool use can be described in terms of quantity and quality as well as how tool use impacts performance.

\subsection{The Nature of the Experienced Learner and Tool Use}

Within Perkins's (1985) framework to increase the probability of effective tool use, two main types of learner variables are emphasized. Perkins suggests that (a) not only the tool should be present and hence functional, but also (b) learners should be able to recognize the tools' functionality and (c) learners should be motivated to use the tool(s). This means that (a) using the tools will have significant effects on learning, that (b) the learners' ability to recognize the functionality of the tool(s) implies that learners do not only recognize tools' functionality but also know the relationship between the tools and learning. This process entails metacognitive thinking (variables). Lastly, it implies that (c) the learners' motivation that might encourage tool use implies motivational variables. Consequently, metacognitive, and motivational variables seem crucial to understand optimal tool use.

Metacognitive variables are related to the knowledge learners have about relationships between tools and learning (Elen, Lowyck, \& Proost, 1996). In this sense, metacognitive variables give an indication of learners' (meta-) understanding of how using tools will help them enhance their own learning (Elen et al., 1996). Self-regulated learning (skills) perceptions and (instructional) conceptions (Gerjets \& Hesse, 2004; Lowyck, Elen, \& Clarebout, 2004), are examples of metacognitive variables that have been emphasized in investigations on tool use (e.g., Aleven et al., 2003; Hartley \& Bendixen, 2001; Lowyck et al., 2004). Evidence suggests that there is a relationship between the tool usage and learner's self-regulated learning skills (Greene \& Azevedo, 2007). When tools are used, learners that are self-regulated obtain significant higher learning gains in comparison with low self-regulated learners (Lajoie \& Azevedo, 2006; Pressley, Snyder, Levin, Murray, \& Ghatala, 1987). Moreover, high self-regulators seem to use tools more qualitatively (Clarebout et al., 2010).

Learners' conceptions and perceptions have also been described as a type of metacognitive variable (Elen \& Clarebout, 2006). Perceptions could be learners' interaction of their conceptual residue of experiences (i.e., conceptions of ideas and theories on tools and tool usage) with the learning environment (Lowyck et al., 2004). Theoretically, it has been suggested that conceptions and perceptions determine whether or not or how tools will be used (Gerjets \& Hesse, 2004; Winne, 1985). Based on this assumption, if the tools' functionalities are not conceived or perceived correctly, then tool use is ineffective. However, empirically speaking, the role of conceptions and perceptions on tool use still remains scarce (Gerjets \& Hesse, 2004; Lowyck et al., 2004), and the existing literature has revealed no effects of conceptions and/or perceptions on tool use (e.g., Clarebout \& Elen, 2009). In neighboring fields, the Technology Acceptance Model (TAM) (Davis, Bagozzi, \& Warshaw, 1989) specifies two kinds of perceptions (perceived usefulness and perceived ease of use) that influence system use. The TAM, however, focuses on the adoption of a system such as text editors, e-mails, spreadsheets, Microsoft Windows, personal computing (Legris, Ingham, \& Collerette, 2003). Based on the TAM perceptions, and in an attempt to specify perceptions for tool use in CBLEs, research has specified two kinds of perceptions for tool use in CBLEs (Collazo, Elen, \& Clarebout, 2012), which we will focus on. These are, first of all, perceived tool functionality, that is, the degree to which a learner believes that using a certain tool would enhance their performance in order to reach a goal; secondly, perceived tool usability, that is, the degree to which a learner believes that using a certain tool would be usable and easy to use.

However, even if learners have enough metacognitive skills that would hypothetically influence tool use positively, if they are not motivated to use the tools, tools will be unlikely used (Perkins, 1985; Winne, 1985; Zimmerman, 2000). Motivation, however, is a broad term which derives from many associated constructs exploring different motivational aspects (Murphy \& Alexander, 2000). Empirical and theoretical literature explores motivation in relation to tool use and performance in terms of goal orientation and self-efficacy in CBLEs (Aleven et al., 2003; Murphy \& Alexander, 2000; Newman, 1994; Zimmerman, 2000).

Goal orientation is defined as the set of personal beliefs that reflect the reasons and intentions to engage and achieve a task (Dweck, 1986). Two main goal orientation types have been mostly emphasized which are mastery orientation (defined in intrapersonal terms) and performance orientation (defined in normative terms) (Dweck \& Legget, 1988). These are each operationalized on a scale ranging from mastery and performance avoidance (negative) to mastery and performance approach (positive) (Elliot \& McGregor, 2001). Mastery approach refers to the focus of individuals on developing competence, expanding knowledge, task completion and understanding, learning, mastery, solving problems, and developing new skills. Performance approach is exemplified by learners' concerns about how well they perform and how others perceive their behavior. It focuses on personal ability, a normative social comparison with others, and a desire for public recognition of performance. Mastery avoidance 
and performance avoidance, on the other hand, are conceived to be orientations with a negative valence. Mastery avoidance refers to the focus individuals have about striving to avoid misunderstanding or failing, avoid making mistakes or doing anything wrong or incorrectly from an intrapersonal perspective (Elliot \& McGregor, 2001). Performance avoidance focuses on avoiding normative competence, refers to low competence expectancies, fear of failure and avoidance of failure (Elliot \& Church, 1997; Elliot \& McGregor, 2001).

Research has revealed a negative relationship between goal orientation, specifically, mastery approach and quantity of tool use (time spent on tool) (Clarebout \& Elen, 2009) and a positive relationship between performance goal orientation (approach and avoidance) on quantity of tool use (frequency) (Crippen, Biesinger, Muis, \& Orgill, 2009). However, Huet, Escribe, Dupeyrat, and Sakdavong (2011) reported a significant negative correlation between performance goal orientation (approach and avoidance) and quantity of tool use (frequency of tool use), which means that learners with high performance approach and avoidance accessed the tools less frequently (Huet et al., 2011).

Self-efficacy is the key element of the social cognitive theory (Bandura, 1977). It is defined as personal beliefs about having the means to organize or execute the courses of action to perform effectively (Bandura, 1997), which implies that self-efficacy influences how learners approach goals, tasks, and challenges (Bandura, 1997), in this case tools. Although studies have revealed that high self-efficacious learners increase the frequency to access tools (quantity of tool use) (Wu, Lowyck, Sercu, \& Elen, 2011), evidence has also suggested that the quantity of tool use is negatively influenced by high self-efficacy levels (less frequent tool access) (Jiang \& Elen, 2010). This in contrast to quality of tool use, which is positively influenced (Jiang \& Elen, 2010).

In summary, although highly skilled learners are found to use tools, it remains unclear what and how learner variables are precisely determining effective tool use, which would lead to performance increase.

\subsection{The Characteristics of Tools}

A second line of research focuses on variables that are related to the type of tool and the tool presentation (Schnotz \& Heiss, 2009). This paper will focus on the effects of cognitive tools on tool use (contrary to information tools or scaffold tools (Lust et al., 2012)). Cognitive tools not only enhance, extend or augment thinking, they also help learners accomplish cognitive tasks (Perkins, 1985) and provide opportunities to apply knowledge in meaningful activities (Lajoie \& Azevedo, 2006). For example, the tool for this study, namely a concept map, is believed to be a graphical tool that facilitates meaningful learning by externalizing and structuring knowledge through meaningful relationships between interconnecting concepts, and it helps organize and represent knowledge by means of relationships among concepts (Novak \& Cañas, 2008; Novak \& Gowin, 1984). Based on the characteristics of concept maps, they could be considered "(knowledge organization) cognitive tools" (Iiyoshi \& Hannafin, 1998). This is because they help learners simplify unnecessarily complex cognitive tasks (Cognitive Load Theory) and facilitate self-regulated organization (Metacognition Theory) (Iiyoshi \& Hannafin, 1998).

According to Ruiz-Primo's (2004) directedness continuum, concept maps can range from high-directed to low-directed. High-directed concept maps provide students with the concepts, connecting lines, linking phrases, and the structure of the map. Low-directed concept maps allow learners to decide which, how, and how many concepts they will include in their maps. High-directed concept maps have been often addressed as semi-structured concept maps (Afamasaga-Fuata'i \& McPhan, 2009; Rodriguez, 2006; Zeilik et al., 1997). Zeilik et al. (1997) have made extensive use of semi-structure concept maps with undergraduate students, which had positive effects on learning. This type of concept maps are similar to multiple-choice tests, with the difference that semi-structured concept maps measure connected and hierarchical understanding (Rodriguez, 2006).

The idea of tool presentation mainly refers to whether the use of the tools is obligatory or optional (Schnotz \& Heiss, 2009), which is also appointed as embedded (obligatory) or non-embedded (optional) (e.g., Clarebout \& Elen, 2006; Clarebout et al., 2010). This means, that when tools are embedded, learners have no choice but to use them; whereas when tools are non-embedded, learners have the freedom to decide whether or not to use the tools (Clarebout \& Elen, 2006; Clarebout et al., 2010).

The tool presentation is related to the learner control debate (Lawless \& Brown, 1997). One standpoint on the learning control debate supports the idea of giving the learners control over their learning, for example, in the component display theory (Merrill, 1980, 1983) and thus by non-embedding tools. Another point of view claims that learning is not effective in environments with little control over learning. Regarding results related to tools' presentation, and in line with learner control literature, research indicates that learners with embedded tools perform more optimally (Martens, Poelmans, Daal, \& Valcke, 1993), but having non-embedded tools may have a positive influence on the quality of tool use which in turn influences performance positively (Clarebout et al., 2010). 
Greene and Land (2000) illustrate the role of tool presentation and tool type on tool use in CBLEs. They analyzed undergraduate students' use of non-embedded information tools (internet search engine machine) and embedded scaffold tools (guiding questions) while they worked on a project. The results pointed out that learners' quality of tool use in the non-embedded information tools was low. That means that they had difficulty using the tools properly and their searches were too broad or irrelevant in many of the cases. With respect to the embedded scaffold tool, learners tended to omit questions and/or give superficial answers, resulting in suboptimal tool use.

\subsection{Influencing Tool Use}

A third line of research has explored the use of interventions that may affect tool use (Clarebout et al., 2010). The implementation of interventions has been made in order to increase tool use probabilities and influence optimal tool use without "forcing" the learner by making the tool functionality more discernible (Lowyck et al., 2004). Based on the functionalities learners ascribe to tools, the tool use will be determined (Winne, 1985). Interventions are said to provide guidance during a learning task (Atkinson, 2002), and encourage the use of tools that provide information that the learner has not accessed (Lee \& Lehman, 1993). Interventions can also specify the functionality of the tools as the benefits that can be obtained by using the tool(s) (Clarebout \& Elen, 2008). These interventions have been operationalized as pedagogical agents (Atkinson, 2002), instructional cues (Lee \& Lehman, 1993) and advice (Clarebout \& Elen, 2008), among others. Studies on interventions have revealed positive effects on quantity of tool use and performance (Atkinson, 2002; Lee \& Lehman, 1993), but has also shown mixed effects (Clarebout \& Elen, 2008).

\section{The Present Study}

The theoretical framework described above details the role of different variables that can influence tool use and performance. However, clear and concrete unequivocal research of these effects in a sole investigation has yet to be studied, especially in the case of experienced learners.

Therefore, in a context of graduate learners using a cognitive tool (semi-structured concept maps), this paper, first of all, studies the role of perceptions (perceived tool functionality and perceived tool usability), self-regulated learning skills, goal orientation, and self-efficacy on quantity and quality of tool use. Secondly, it analyzes the effects of tool presentation (embedded and non-embedded tool) on the use of semi-structured concept maps. Third, it examines the influence of an instructional intervention operationalized as the explanation of tool functionality on quantity and quality of tool use. Fourth, this paper explores the possible direct effects of quantity and quality of tool use on performance. Finally and most importantly, in order to see if the tools contribute to performance, effects of conditions on performance were analyzed. Consequently the following research questions are addressed:

(1) Do the different conditions contribute to learners' performance?

(2) Do quantity and quality of tool use influence performance?

(3) What is the effect of perceptions, self-regulated learning, goal orientation and self-efficacy on quantity and quality of tool use?

(4) What is the effect of tool presentation (embedded vs. non-embedded tools) and interventions (non-/explanation of tool) functionality on quantity and quality tool use?

\section{Methodology}

\subsection{Participants}

There were a total of one hundred and seventeen Dutch speaking participants. All participants had a BA degree (with at least three years of learning experience at the university level), and were currently enrolled in the preparatory master program in Educational Studies from the University of Leuven in Belgium. They were on average 23 years old $(S D=4.18)$ and eighty-two percent were female. Based on their average score of the pre-test $(M=5.34, S D=1.36)$, learners were categorized as low prior knowledge learners in which no significant difference among the conditions was observed. As Table 1 confirms, participants were high-skilled and highly motivated learners.

\subsection{Instruments}

\subsubsection{Learning Environment}

A text-in Dutch —on water scarcity titled Waarom water broodnodig is "Why is water essential" (Raes, Geerts, \& Vanuytrecht, 2009) was selected and adapted in format for a Macromedia Director program. The text was comprised of 1,544 words and two figures and was divided into five sections. After each section, there was a 
concept map. A concept map represents visual relationships in intertwined circles (Novak \& Cañas, 2008; Novak \& Gowin, 1984). In this study, the concept maps were represented in the traditional hierarchical fashion, namely the more general concepts were displayed at the top and the less general concepts at the bottom (Novak \& Cañas, 2008). The concept maps were semi-structured, which means that learners had to complete an unfinished concept map with concepts from the text (see Figure 1). There were five conditions (further information see Tables 1 and 4). Two conditions had the explanation of the tool functionality (see Figure 2) one of which had embedded tools and the other one non-embedded tools. The explanation in Figure 2 reads as: "Every concept map will bring up a part of your knowledge. By completing the concept map, you will be able to make a better connection between the information provided and your daily life. You knowledge will also become more meaningful and as a consequence the chances that you will do better in the test will be stronger." Two other conditions did not have any explanation of the tool functionality, and as in the other conditions, one had embedded tools and the other non-embedded tools. In the non-embedded conditions students could press a button to access the tool (see Figure 2). In the embedded conditions, on the other hand, participants did not have this button and by clicking on the button of next page, they directly accessed the tool. One last condition was the control condition, which received neither tools nor tool explanations.

Table 1. Overview of conditions

\begin{tabular}{lccc}
\hline \multicolumn{1}{c}{ Condition } & $\begin{array}{c}\text { Tool } \\
\text { provided? }\end{array}$ & $\begin{array}{c}\text { Embedded } \\
\text { tool? }\end{array}$ & $\begin{array}{c}\text { Explanation of tool } \\
\text { functionality? }\end{array}$ \\
\hline Control Condition & No & N/A & N/A \\
Non-embedded, Explained Functionality & Yes & No & Yes \\
$\begin{array}{l}\text { Embedded, Explained Functionality } \\
\text { Non-embedded, Non-explained }\end{array}$ & Yes & Yes & Yes \\
functionality & Yes & No & No \\
Embedded, Non-explained functionality & Yes & Yes & No \\
N/A: Non-applicable & & & \\
\hline
\end{tabular}




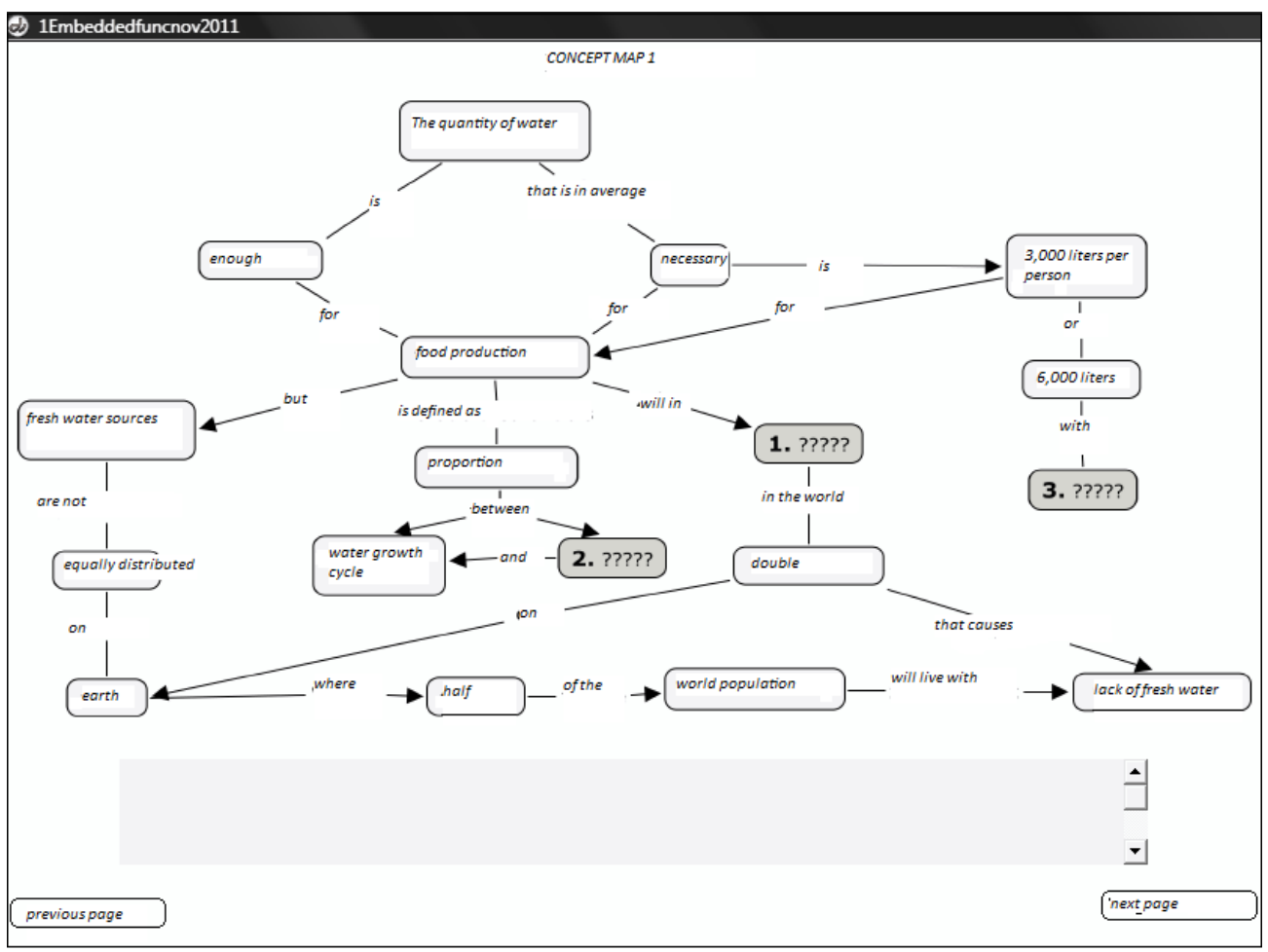

Figure 1. Tool employed in the form of concept maps

Note. Concepts enclosed in boxes. The empty concepts in darkened boxes with number 1, 2 and 3 and question marks had to be filled in the darkened space below the concept map. This concept map is a translation from the original one version which was in Dutch

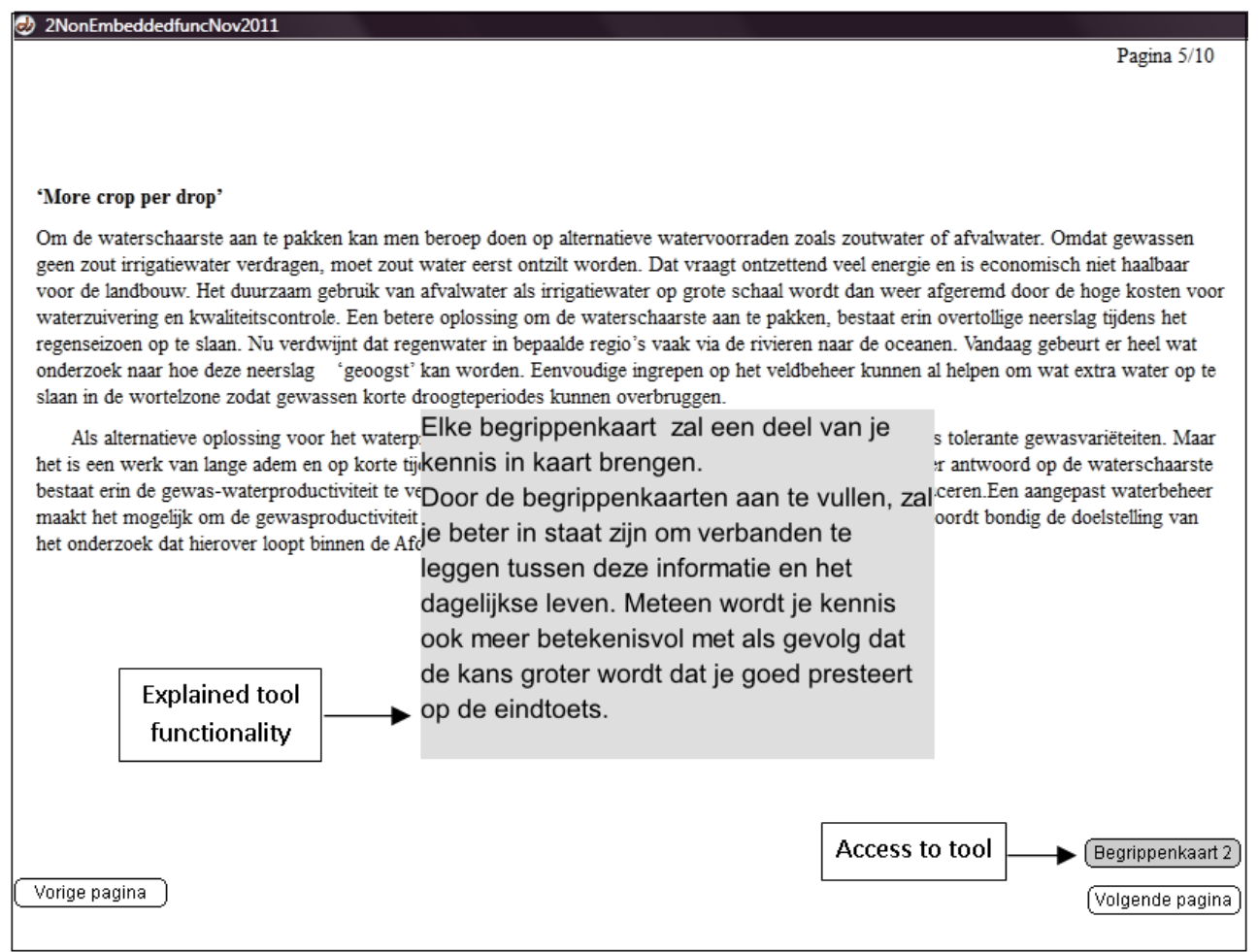

Figure 2. Example of non-embedded condition with explained tool functionality

Note. The box in gray appeared after students clicked on "volgende pagina" (next page). 


\subsubsection{Perceptions}

The questionnaire of perceived usefulness (Davis, 1989), system functionality (Pituch \& Lee, 2006) and perceived functionality (Cho et al., 2009) were integrated into a single questionnaire to explore perceived functionality. This questionnaire has previously been used and shown high reliabilities; (above. 80, Juarez-Collazo et al., 2012) and has integrated the three questionnaires in order to have a broader view of perceived tool functionality. The questionnaire consisted of 15 questions. For perceived usability, the questionnaire on perceived ease of use (Davis, 1989) was employed. Both questionnaires were adapted to tool use and translated into Dutch by three different researchers using the translation/back translation method in order to avoid semantic problems (Behling \& Law, 2000). In each questionnaire participants responded on a six-point Likert scale where one indicated totally disagree and six totally agree.

\subsubsection{Self-Regulating Skills}

To measure self-regulated learning skills, we used a selection of the LIST questionnaire (Wild \& Schiefele, 1994) which was translated in Dutch and has been used in earlier research showing high reliabilities (e.g., Clarebout et al., 2010; Wild \& Schiefele, 1994). The selection included six out of the eleven elements. The selection included elements that were applicable to individual study learning materials. Those elements related to discussing learning materials with others were discarded. As a result, the items from elements appointed as organization, elaboration, repetition, monitoring/planning, critical thinking and effort were included and measured on a six-point Likert scale (one, totally agree; six, totally disagree). Organization focuses on the activities that are performed to reorganize learning material to perform optimally (e.g., I make tables, figures or drawings to structure course content better). Elaboration is related to study activities that are appointed towards a deeper understanding of the learning material (e.g., I try to make connections with related topics). Critical thinking focuses on activities that deepen the understanding of the material through a critical analysis of statements and justification contexts (e.g., What I learn, I examine critically). Repetition is related to the memorization of facts and rules by simply repeating (e.g., I memorize the text content by repeating). Monitoring/planning focuses on "planning" and "monitoring" that serve to control the current self-regulation learning processes (e.g., Before I start to study my learning material, I think about how I can proceed most effectively). Lastly, effort covers the extent to which increased efforts will be actively used to achieve academic and learning goals (e.g., I don't give up, even if the material is complex).

\subsubsection{Goal Orientation}

Goal orientation was measured by integrating two questionnaires of Elliot et al. (Elliot \& Church, 1997; Elliot \& McGregor, 2001). The initial questionnaire of Elliot and colleagues (Elliot \& Church, 1997) only measured three dimensions of goal orientation (mastery approach, performance avoidance, and performance approach); the revised and employed questionnaire (Elliot \& McGregor, 2001) incorporated mastery avoidance and mastery approach making a $2 \times 2$ framework of goal orientation (performance avoidance, performance approach, mastery avoidance and mastery approach). We employed the same translation procedure as in the perceptions questionnaires. A six-point Likert scale was employed where one indicated totally disagree and six totally agree.

\subsubsection{Self-Efficacy}

The questionnaire consisted of eight questions using elements from the Motivated Strategies for Learning Questionnaire (MSLQ) (Pintrich, Smith, Garcia, \& McKeachie, 1991) and the Self- and Task-Perception Questionnaire (STPQ). This adaptation has previously been used and shown high Cronbach alpha's reliabilities above .80 (e.g., Jiang \& Elen, 2010; Juarez-Collazo, Lust, Elen, \& Clarebout, 2011). As in the previous questionnaires, participants responded on a six-point Likert scale.

\subsubsection{Quantity of Tool Use}

Quantity of tool use was analyzed in two ways: the frequency learners accessed the tools, that is, the amount of clicks made on the link to access tools in non-embedded conditions only and the proportional time participants spent on the tool (all conditions). Both clicks and time spent on the tool were saved in log files. The time spent on the tool was recorded in seconds.

\subsubsection{Quality of Tool Use}

Quality of tool use was analyzed through the answers provided in the concept maps blank boxes. Each concept map $(N=5)$ had three boxes to be completed. In each box, learners had to give the correct/exact concept based on the text they were reading. The exact concept or synonym to the exact concept was awarded with one point. For example in Figure 1, the answer to the empty concept number 3 is "meat consumption". Learners who answered "non-vegetarian diet", for instance, were also awarded a point. Other answers, such as "diet", for 
example, were given zero points. This kind of answers reflected that the learners did not read thoroughly, and thus did not include the tools in their learning process (low quality of tool use). If learners obtained the answers for each concept map correct, they could obtain a maximum of 15 points. The answers on the concept maps were recorded as text files that were retrieved and revised after the participant concluded the activity.

\subsubsection{Learning Outcomes}

A pre-test was conducted in order to see if learners differ regarding their prior knowledge. The test consisted of ten multiple-choice questions where learners could obtain a maximum of 10 points. Performance was measured through a post-test that participants answered after they finished the hypertext task. It consisted of 16 items, seven of which were multiple-choice items, three were fill-in-the-blank sentences and the last six items were true or false statements. Participants could obtain a point for every correct answer, thus they could obtain a maximum score of 16 in the post-test.

\section{Procedure}

The experiment was spread over two sessions. During the first session, two researchers distributed the questionnaires to all participants who were in an auditorium following their Learning and Instruction class. They filled out the questionnaires on perceptions, self-regulated learning, goal orientation and self-efficacy. Afterwards, participants had the possibility to enroll in one of the 14 sessions available. A maximum of 15 participants could attend each session. The second session was the "computer" session. Herein participants entered the room and sat in front of a computer. Participants were told about the structure of the second session. The hypertext started on page three. When the participants concluded with the hypertext, they were given the performance tests.

For data analysis, reliabilities for the different scales measuring the learner variables were conducted and descriptive statistics were performed in order to identify how participants are positioned on the different learner variables scales. A check using MANOVA was also performed to see if there were any differences among the different conditions (experimental and control) regarding the learner variables (including the prior knowledge pre-test). The post-test (performance) was also included as dependent variable in this analysis in order to answer question one. In addition, descriptive statistics were included.

To explore the possible effects of tool use on performance (second research question), a simple regression was performed with both indicators of quantity of tool use (only time) and quality of tool use as independent variables and performance as dependent variable. Then, we conducted a second regression with frequency of tool use as independent variable and performance as dependent variable. The control condition was not considered for these analyses. Next, to observe the relationships among all aspects of tool use (time, frequency, and quality), a correlation analysis was conducted.

To identify whether any learner variables influenced tool use (research question three), three different multiple regression analyses were conducted. One analysis used the learner variables as independent variables and quantity (time spent on tool) as dependent variable. A second analysis had quality of tool use as a dependent variable. The last regression - only with non-embedded conditions - was conducted with the same independent variables and quantity of tool use (frequency) as the dependent variable. In case any covariate was found, the regression model was run in two blocks, putting in the first block the covariates and in the second block the other predictor variables.

For the last research question (What is the effect of tool presentation, i.e., embedded vs. non-embedded tools) and the intervention (i.e., explanation of tool functionality), a MANOVA with the experimental conditions as independent variable and quantity (only time spent on tool) and quality of tool use as dependent variables was run. Next, a separate ANOVA was done to analyze the effects of the experimental non-embedded conditions on frequency of tool use.

\section{Results}

\subsection{The Nature of the Experienced Learner}

Reliabilities, shown in Table 2, appeared overall appropriate. As a consequence all the scales were included in the analyses. The descriptive statistics (Table 2) indicate that the means for the different learner variables scales were between 3.09 and 4.79, pointing out that learners' differences are not pronounced on one of the scales. The descriptive statistics per condition show similar results. This table can be observed in appendix A. Thus, learners seemed highly skilled as highly motivated. 
Table 2. Descriptive statistics of all learner variables including reliability scales confirming strong learning skills and high motivation

\begin{tabular}{llcccc}
\hline & $\mathrm{N}$ & $M$ & $S D$ & $\alpha$ \\
\hline Perceived Functionality & 117 & 3.80 & .69 & .89 \\
Perceived Usability & 117 & 3.78 & .77 & .82 \\
Self-efficacy & 117 & 3.63 & .71 & .89 \\
Goal orientation: & & & & & \\
& Performance Approach & 117 & 3.09 & .97 & .89 \\
& Master Approach & 117 & 4.79 & .58 & .71 \\
& Performance Avoidance & 117 & 3.71 & .96 & .84 \\
& Master Avoidance & 117 & 4.34 & 1.13 & .88 \\
Self-regulation: & & & & & \\
& Organization & 117 & 4.43 & .81 & .80 \\
& Elaboration & 117 & 4.30 & .78 & .86 \\
& Repetition & 117 & 4.48 & .92 & .71 \\
& Metacognition & 117 & 4.24 & .61 & .73 \\
& Critical Thinking & 117 & 3.30 & .78 & .82 \\
& Effort & 117 & 4.31 & .81 & .77 \\
\hline
\end{tabular}

The MANOVA analysis indicated that there was no significant difference among conditions regarding perceptions, goal orientations, self-efficacy, self-regulation, prior knowledge and performance (Wilks' statistics $\Lambda=0.53, \mathrm{~F}(60,384)=1.15, \mathrm{p}=.22$, partial $\left.\eta^{2}=.15\right)$. However, given that the results using Roy's largest root were significant $\left(\Theta=0.29, \mathrm{~F}(15,101)=2.00, p<.05\right.$, partial $\left.\eta^{2}=.23\right)$, we examined the separate follow-up ANOVAs. The ANOVAs suggested that in two subscales of self-regulated learning there was a significant difference among conditions. These scales were critical thinking $\left(\mathrm{F}(4,112)=3.41, p<.05\right.$, partial $\left.\eta^{2}=.11\right)$ and repetition $\left(\mathrm{F}(4,112)=2.49, p<.05\right.$, partial $\left.\eta^{2}=.08\right)$. Consequently, in the further analyses (question 4$)$ critical thinking and repetition were considered as covariates.

\subsection{Performance of the Learner}

5.2.1 Research Question 1: Do the Different Conditions Contribute to the Learners' Performance?

Table 3 illustrates the descriptive statistics with the number of participants per condition, the performance mean scores, the standard deviations, the representative percentages of the raw mean scores and the percentage relative standard deviation. The separate ANOVAs pointed out that there was no significant difference in prior knowledge $\left(\mathrm{F}(4,112)=1.20, \mathrm{p}=.32\right.$, partial $\left.\eta^{2}=.04\right)$ or in performance $\left(\mathrm{F}(4,112)=1.38, \mathrm{p}=.25\right.$, partial $\left.\eta^{2}=.05\right)$ among conditions. These results confirm that learners were quite experienced. Even though the overall mean value of prior knowledge of the material was relatively low $(M=53.38)$, learners were able to increase their understanding of the domain up to a very high level (Avg. $M=85.78$ ).

Table 3. Descriptive statistics showing performance in each condition

\begin{tabular}{lccc}
\hline Condition & $\mathrm{N}$ & $M$ & $S D$ \\
\hline Control Condition & 23 & 13.35 & 2.31 \\
Non-embedded, Explained Functionality & 24 & 13.21 & 1.74 \\
Embedded, Explained Functionality & 23 & 13.91 & 2.07 \\
Non-embedded, Non-explained functionality & 24 & 14.29 & 1.63 \\
Embedded, Non-explained functionality & 23 & 13.87 & 1.29 \\
\hline
\end{tabular}




\subsubsection{Research Question 2: Do Quantity and Quality of Tool Use Influence Performance?}

The regression analyses shown in Table 4 suggested that both aspects of quantity of tool use (time and frequency) influenced performance significantly. Time spent on tool had a positive effect on performance which means that the more time the learners spent on the tool, the better the results in the post-test. However, the frequency of tool use revealed a negative relationship with performance, which means that the more times the tool was accessed, the poorer the results in the post-test. Time spent on the tool accounted for $6.76 \%$ of the variance whereas frequency of tool use accounted for $12.96 \%$ of the variance. Quality of tool use, on the other hand, showed no significant effects on performance (it only accounted for $1.69 \%$ of the variance). For the first regression model, VIF values were well below 10, namely 1.01 and the average VIF was 1.01 .

Table 4. Regression with tool use and performance

(1) Performance

All conditions

\begin{tabular}{lccc}
\hline & B & $\boldsymbol{S E} \boldsymbol{B}$ & $\boldsymbol{\beta}$ \\
\hline (Constant) & 11.04 & 1.26 & \\
Quantity (time on tools) & .002 & .001 & $.26^{*}$ \\
Quality tool use & .13 & .10 & .13
\end{tabular}

Note (1): $R^{2}=.08, p<.05$.

Note (2): $\mathrm{R}^{2}=.13, p<.05$.

$* p<.05$
(2) Performance

Non-embedded conditions

\begin{tabular}{lccc}
\hline & B & $\boldsymbol{S E} \boldsymbol{B}$ & $\boldsymbol{\beta}$ \\
\hline (Constant) & & & \\
Quantity (frequency) & -.07 & .03 & -.36 \\
& & & \\
\hline
\end{tabular}

The further correlation analysis among quantity (time and frequency) and quality of tool use showed a significant relationship; namely, quality of tool use and frequency of tool use were significantly correlated $r$ $=.36, p<.05$ at two-tailed.

\subsection{What Influences Tool Use?}

5.3.1 Research Question 3: What Is the Effect of Perceptions, Self-Regulated Learning, Goal Orientation and Self-Efficacy on Quantity and Quality of Tool Use?

Given that high-skilled learners scored high and their performance was influenced by quantity of tool use, it is important to see what learner variables specifically influenced this tool use. Table 5 shows the effects of the different learner variables on tool use. Hierarchical regression analysis (in two steps) was run in order to control for the subscales of critical thinking and repetition (covariates). In the first step, the covariates were examined alone to observe the isolated effects on these variables on quantity (time and frequency) and quality of tool use. The results show that critical thinking had positive significant effects on quality of tool use but significant negative influence on quantity of tool use, specifically, time spent on tools. Each of these effects explained 4.84\% of the variance in tool use. 
Table 5. Hierarchical regression with learner variables and tool use

\begin{tabular}{|c|c|c|c|c|c|c|c|c|c|}
\hline & \multicolumn{3}{|c|}{ (1) Quality of tool use } & \multicolumn{3}{|c|}{$\begin{array}{l}\text { (2) Quantity of tool use: } \\
\text { time spent on tools }\end{array}$} & \multicolumn{3}{|c|}{$\begin{array}{l}\text { (3) Quantity of tool use: } \\
\text { frequency on tools }\end{array}$} \\
\hline & B & SE B & $\beta$ & B & SE B & $\beta$ & B & SE B & $\bar{\beta}$ \\
\hline \multicolumn{10}{|l|}{ Step 1} \\
\hline (Constant) & 13.80 & 1.51 & & 499.45 & 176.32 & & 30.27 & 9.66 & \\
\hline Critical thinking & -.53 & .25 & $-.22 *$ & 63.24 & 29.85 & $.22 *$ & -.44 & 1.72 & -.04 \\
\hline Repetition & -.10 & .23 & -.05 & -16.41 & 27.07 & -.06 & -1.04 & 1.54 & -.10 \\
\hline \multicolumn{10}{|l|}{ Step 2} \\
\hline (Constant) & 14.81 & 2.45 & & 131.06 & 275.37 & & 35.06 & 17.75 & \\
\hline Critical thinking & -.37 & .40 & -.15 & -12.94 & 45.14 & -.05 & -.81 & 3.07 & -.07 \\
\hline Repetition & -.08 & .29 & -.03 & -8.28 & 33.00 & -.03 & -.28 & 1.93 & -.03 \\
\hline Organization & -.31 & .29 & -.13 & -67.87 & 32.59 & $-.25^{*}$ & 3.20 & 2.27 & .31 \\
\hline Elaboration & .00 & .43 & .00 & 96.78 & 47.77 & $.35^{*}$ & -1.28 & 2.98 & -.10 \\
\hline Monitoring/planning & -.19 & .48 & -.06 & 16.05 & 53.77 & .04 & 1.28 & 3.39 & .09 \\
\hline Effort & .52 & .32 & .22 & 13.31 & 35.77 & .05 & 3.80 & 2.21 & .33 \\
\hline Performance Approach & -.05 & .23 & -.03 & -13.64 & 26.18 & -.06 & -3.93 & 2.41 & -.39 \\
\hline Master Approach & -.53 & .45 & -.16 & 23.08 & 50.07 & .06 & -4.41 & 3.45 & -.31 \\
\hline Performance Avoidance & .11 & .29 & .06 & 9.26 & 32.68 & .04 & -2.44 & 2.20 & -.29 \\
\hline Master Avoidance & .20 & .28 & .12 & 21.08 & 31.17 & .11 & 2.81 & 2.31 & .36 \\
\hline Perceived Functionality & -.19 & .41 & -.07 & -54.80 & 46.15 & -.17 & -6.43 & 3.80 & -.57 \\
\hline Perceived Usability & -.21 & .36 & -.09 & 81.50 & 39.99 & $.30^{*}$ & 1.51 & 2.93 & .14 \\
\hline Self-efficacy & .33 & .32 & .13 & 11.17 & 35.84 & .04 & 2.85 & 3.19 & .24 \\
\hline
\end{tabular}

Note (1): $R^{2}=.05, p=.12$ for Step $1 . \Delta R^{2}=.10, p=.64$ for Step 2 .

Note (2): $\mathrm{R}^{2}=.06, p=.06$ for Step $1 . \Delta R^{2}=.16, p=.15$ for Step 2 .

Note (3)-non-embedded conditions only-: $\mathrm{R}^{2}=.01, p=.78$ for Step $1 . \Delta \mathrm{R}^{2}=.20, p=.68$ for Step 2.

$* p<.05$

After controlling for critical thinking and repetition in the second model, the significance effects of critical thinking disappeared in both quality and quantity of tool use (time) and further significant relationships were retrieved. The subscales of self-regulated learning, namely organization and elaboration, and perceived tool usability revealed a significant effect on quantity of tool use (time) (see Table 5). Organization had a negative influence on quantity of tool use (time), which accounted for $6.25 \%$ of the variance. This suggests that strong self-organizers do not need tools as much as other learners. Elaboration and perceived usability both had a positive effect on quantity of tool use (time). The effect of elaboration accounted for $12.25 \%$ of the variance whereas perceived usability accounted for $9 \%$ of the variance in the outcome. For our model, the tolerance was above 0.2 , it ranged from .34 to .94 . The VIF values were well below 10, ranging from 1.1 to 2.6 , and the average VIF was 1.98.

Specifically, the established effect of the self-regulated learning skill of elaboration suggests that the more learners were oriented towards a deeper understanding by means of study activities, in this case the use of tools, the more time they spent on tools. The finding on the role of perceived tool usability, on the other hand, indicates that the more learners believed that using a certain tool would be usable and easy to use, the more time they spent on it.

Effects of the other subscales of self-regulated learning, perceived tool functionality and the motivational variables of goal orientation, self-efficacy and on quantity of tool use (time) could not be retrieved. As for the other aspects of tool use (frequency and quality of tool use), no learner variables showed a significant relationship either. A correlation table can be observed in Appendix B. 
5.3.2 Research Question 4: What Is the Effect of Tool Presentation (Embedded vs. Non-Embedded Tools) and Interventions (Non-/Explanation of Tool Functionality) on Quantity and Quality Tool Use?

To understand whether interventions and tool presentation had an impact on tool use, we performed a MANOVA analysis, which showed that there was a significant effect of tool presentation and interventions (non-/embeddedness and non-/explained tool functionality) on quantity (time) and quality of tool use using Wilks' statistics $\left(\Lambda=0.75, \mathrm{~F}(6,176)=4.59, \mathrm{p}<.001\right.$, partial $\left.\eta^{2}=.14\right)$. The separate ANOVAs on the outcome variables only revealed a significant effect of condition on quantity of tool use, specifically, time spent on the tool $\left(\mathrm{F}(3,89)=8.94, p<.001\right.$, partial $\left.\eta^{2}=.23\right)$, but not on quality of tool use $\left(\mathrm{F}(3,89)=.90, p=.45\right.$, partial $\eta^{2}$ $=.03$ ). The Tukey post hoc tests revealed that the embedded condition without explained functionality spent significantly more time on the tools than the embedded and non-embedded conditions with explained functionality ( $p \mathrm{~s}<.005$ and $<.001$, respectively). The non-embedded condition without explained functionality also spent significantly more time on tools than the conditions with explained functionality (embedded $p \mathrm{~s}<.05$ and non-embedded $p \mathrm{~s}<.001$ ). This means that the tool intervention (explained functionality) played a more relevant role in the relationship on tool use than the tool presentation (non-/embedded) and conditions without explained functionality spent proportionally more time on the tools than conditions with explained functionality (see Figure 3).

Finally, the separate ANOVA analysis that was conducted to examine the possible effects of condition (only non-embedded without explained functionality) on frequency of tool use showed no significant effects $(\mathrm{F}(1,45)$ $=.52, \mathrm{p}=.47$, partial $\left.\eta^{2}=.01\right)$.

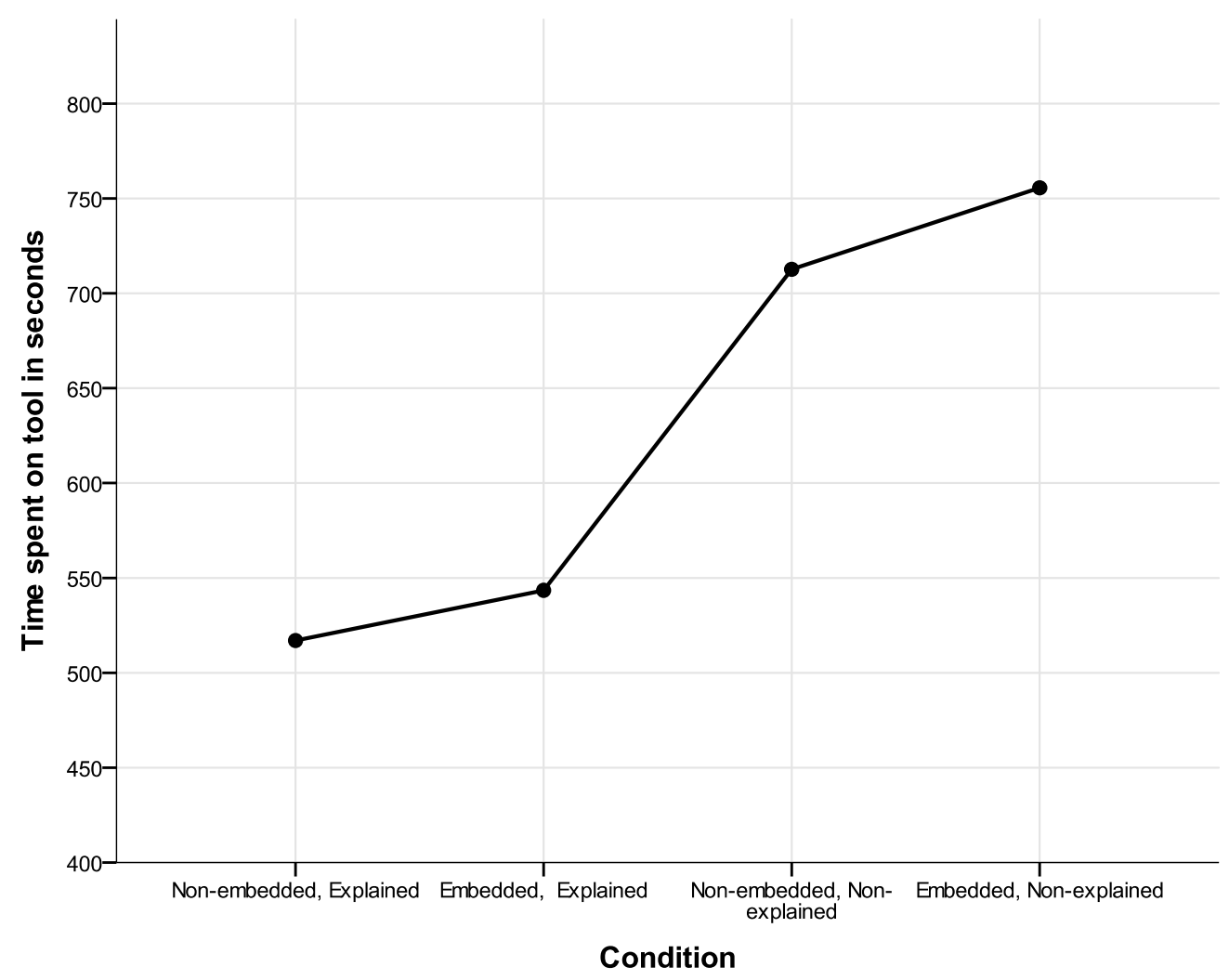

Figure 3. Graph depicting the differences among conditions and quantity of tool use (time)

\section{Discussion}

\subsection{Learner and Tool Variables on Tool Use}

This study was conducted in a CBLE using semi-structured concept maps as tools and a population considered to be "experienced", in this case graduate students. Within this context, we investigated the relationships between metacognitive (perceptions and self-regulated learning) and motivational (goal orientation and self-efficacy) learner variables, tool variables, (tool presentation: non-/embedded tool), interventions (non-/explained tool 
functionality), on quantity and quality of tool use. Furthermore, this study also set out to determine the relationships between quantity and quality of tool use and performance, as well as, the influence of tools on performance. Our results pointed out that the group of participants was very homogeneous and showed little variation. The average results on each of the scales of the learner variables showed that learners gave themselves high scores.

The findings suggest that there is a strong relationship between metacognitive variables and the time spent on the tools. Metacognitive variables have an indirect impact on performance as the time on tools showed a positive influence on learning outcomes. The fact that motivational variables did not contribute significantly to tool use may be an indicator that experienced learners do not need to be self-efficacious or goal oriented. Metacognitive variables may have either moderated or overpowered the effect of motivational variables, given that learners with sufficient self-regulatory skills have the ability to monitor their understanding and willingness to set goals (Hartley \& Bendixen, 2001).

Additionally, the effects of tool presentation were not as strong as previous evidence suggests (e.g., Clarebout et al., 2010). It was the interventions that had stronger effects on tool use. This effect was negative suggesting that learners in the conditions without interventions, that is, without the explained tool functionality used tools more by spending proportionally more time on them. Within the learner control research, effective performance results from the interaction of the learners' internal processes (ability to select and sequence strategies) and the stimulus materials (in this case tools) (Merrill, 1980). The learners in this study showed through their metacognitive variables (specifically self-regulation skill of elaboration and perceived tool usability - which showed an effect on tool use) their capability to regulate their internal processes. Therefore, the explanation of tool functionality may not help experienced learners and may therefore discourage them from using the tools in a CBLE. Therefore, the explanation of tool functionality may not always result in more optimal tool use as previously suggested (Winne, 1985) and reported (e.g., Clarebout \& Elen, 2009). Moreover, these experienced learners may also see the explanation of the functionality as directed to novice learners and hence avoided the explanation because they saw it as a threat to their learning (Rogers \& Freiberg, 1994).

\subsection{Tool Use and Performance}

Quantity of tool use, namely time spent on the tool, showed a positive relationship with performance. This relation was also strong $(12.96 \%$ variance) given the specific population we investigated. This result is in line with previous research (e.g., Clarebout et al., 2010; Viau \& Larivée, 1993). Viau and Larivée (1993) found not only a positive effect of time spent on tool, but also of frequency of tool use in performance. Our results also suggest an indirect effect of perceived tool usability and elaboration on performance, while explained tool functionality and self-organization had a negative indirect influence on performance.

The other aspect of quantity of tool use, namely frequency of tool use, showed a negative influence on performance. Similarly, Jiang and Elen (2011) found that frequent use of cognitive tools, namely questions, led to poor performance. It appeared that reading back and forth between questions and paragraphs prompted high frequency of tool access which affected performance negatively (Jiang \& Elen, 2011). Possibly learners, in this study, encountered difficulties while searching answers (also by going back and forth) for the concept maps which similarly occurred in previous research (Cerdán, Vidal-Abarca, Martínez, Gilabert, \& Gil, 2009).

Moreover, although quality of tool use did not have a significant influence on performance as found in previous research (e.g., Clarebout et al., 2010; Jiang \& Elen, 2011); a significant positive correlation between quality of tool use and frequency was found. This result suggests that the high frequency of tool use is closely related to the quality of tool use and together affect performance negatively. This finding also suggests that non-embedded tools may hamper performance indirectly. Possibly for these experienced learners, in order to obtain more learning gains, embedding tools and allowing enough time on the tools seems more relevant than non-embedding tools and other measures of tool use (in this case quality and frequency of tool use).

\subsection{Tool Effects on Performance}

No difference among experimental and control conditions was observed in relation to performance. These results are related to previous studies (Martens, Valcke, \& Portier, 1997; Zumbach, 2009). Martens, Valcke and Portier saw no difference among conditions with different tool variables in a CBLE and conditions without a CBLE. Martens and colleagues implied that CBLEs were as effective as non-CBLEs. Zumbach obtained his results comparing two experimental conditions (with a mind mapping tool and a two-columned text argumentation tool) with a control condition. Even though he found no advantages or disadvantages of the use/not use of tools on performance, he suggested that intrinsic motivation was larger in the experimental groups. Our results tell us, first, that experienced students without tools, interventions, or different tool presentations can perform similarly 
to students facing all the variables aforementioned. Second, they suggest that tool variables and interventions do not harm or help learning outcomes (performance).

In order to maximize the positive effects of tools, interventions, or different tool presentations in CBLEs, one has to make sure that learners are put in the "right" condition (Martens et al., 1997). In our case, learners at this level should be trusted to have the wisdom of knowing how tools help. Patronizing or underestimating students - in this case through the explanation of the tool functionality - whether they have prior knowledge or not, does not make learning environments (computer or otherwise) any better. These results are limited by the fact that, as also one of the reviewers indicated, the only tool used here was a semi-structured concept map. Future studies should include more low-directed concept maps. It is possible that experienced learners can benefit more from these types of tools.

\section{Conclusion}

Overall, this paper has given account of the problem that surrounds the use of tools in CBLEs and adds to the literature of tool use in CBLEs. Instructional designers or teachers should be aware that interventions, in this case explained functionality, may not be needed with learners with certain educational experience. It seems that such interventions have a negative impact on the time experienced learners spent on tools. It also appears that the explanation of tool functionality moderates the influence of tool presentation on tool use.

Another contribution to research in CBLE based on the results of this study focuses on the relationships between learner variables and tool use. Although motivational variables (goal orientation and self-efficacy) did not affect tool use, their effects could be moderated by the effects of metacognitive variables (self-regulated learning and perceptions) on tool use which role was significant. The relevance of self-regulated learning and perceptions was clearly supported by our findings in which perceived tool usability, self-regulated learning: elaboration and organization showed a significant relationship on quantity of tool use (time spent on tool), the latter a negative one.

A third contribution of this paper is that whereas the time spent on the tool had a positive impact on performance, frequency of tool use had a negative impact on performance. The negative effect of frequency of tool use on performance also relates indirectly to quality of tool use given that it showed a positive correlation to frequency of tool use. This finding questions whether quality of tool use, frequency of tools use and indirectly non-embeddedness of tools harm a potentially useful tool by causing it to become dysfunctional if overused. One of the implications that emerge from this finding relate specifically to whether frequency of tool use and quality could be measurements that should be considered when dealing with experienced learners. Similarly, the relevance of experienced learners in CBLEs is clearly supported when we could observe that there was no difference in performance between experimental conditions and control condition. More importantly, our findings question whether implementing tools in homogeneous groups with more experienced learners is relevant.

Finally, these concluding remarks suggest courses of action in designing CBLEs for experienced learners. While it is clear that tools should be made available for learners in CBLEs giving experienced learners control of their learning, and thus by not embedding tools and avoiding explanation of tools' functionalities, is an important practical implication for CBLEs.

\section{Acknowledgements}

The authors express gratitude to the Fonds Wetenschappelijk Onderzoek—Vlaanderen (FWO) grant G.0408.09 that provided the funds for this research. We would also like to thank Griet Lust for her help with the log files

\section{References}

Afamasaga-Fuata'i, K., \& McPhan, G. (2009). Concept maps as innovative learning and assessment tools in primary schools. In K. Afamasaga-Fuata'i (Ed.), Concept mapping in mathematics (pp. 87-113). US: Springer. http://dx.doi.org/10.1007/978-0-387-89194-1

Aleven, V., Stahl, E., Schworm, S., Fischer, F., \& Wallace, R. (2003). Help seeking and help design in interactive learning environments. Review of Educational Research, 73(3), 277-320. http://dx.doi.org/10.3102/00346543073003277

Atkinson, R. K. (2002). Optimizing learning from examples using animated pedagogical agents. Journal of Educational Psychology, 94(2), 416-427. http://dx.doi.org/10.1037/0022-0663.94.2.416

Bandura, A. (1977). Social learning theory. New York: General Learning Press.

Bandura, A. (1997). Self-efficacy: The exercise of control. New York: W.H. Freeman and Company. 
Cerdán, R., Vidal-Abarca, E., Martínez, T., Gilabert, R., \& Gil, L. (2009). Impact of question-answering tasks on search processes and reading comprehension. Learning and Instruction, 19(1), 13-27. http://dx.doi.org/10.1016/j.learninstruc.2007.12.003

Clarebout, G., \& Elen, J. (2006). Tool use in computer-based learning environments: Towards a research framework. Computers in Human Behavior, 22(3), 389-411. http://dx.doi.org/10.1016/j.chb.2004.09.007

Clarebout, G., \& Elen, J. (2008). Advice on tool use in open learning environments. Journal of Educational Multimedia and Hypermedia, 17(1), 81-97. http://dx.doi.org/10.1007/s11251-008-9068-3

Clarebout, G., \& Elen, J. (2009). The complexity of tool use in computer-based learning environments. Instructional Science: An International Journal of the Learning Sciences, 37(5), 475-486.

Clarebout, G., Horz, H., Schnotz, W., \& Elen, J. (2010). The relation between self-regulation and the embedding of support in learning environments. Educational Technology Research and Development, 58(5), 573-587. http://dx.doi.org/10.1007/s11423-009-9147-4

Crippen, K. J., Biesinger, K. D., Muis, K. R., \& Orgill, M. (2009). The role of goal orientation and self-efficacy in learning from web-based worked examples. Journal of Interactive Learning Research, 20(4), 385-403.

Davis, F. D., Bagozzi, R. P., \& Warshaw, P. R. (1989). User acceptance of computer technology: A comparison of two theoretical models. Management Science, 35(8), 982-1003. http://dx.doi.org/10.1287/mnsc.35.8.982

Dweck, C. S. (1986). Motivational processes affecting learning. American Psychologist, 41(10), 1040-1048. http://dx.doi.org/10.1037/0003-066X.41.10.1040

Dweck, C. S., \& Legget, E. L. (1988). A social-cognitive approach to motivation and personality. Psychological Review, 95(2), 256-273. http://dx.doi.org/10.1037/0033-295X.95.2.256

Elen, J., \& Clarebout, G. (2006). The use of instructional interventions: Lean learning environments as a solution for a design problem. In J. Elen, \& R. Clark (Eds.), Handling complexity in learning environments: Theory and research. Advances in Learning and Instruction (pp. 185-200). Amsterdam: Elsevier.

Elen, J., \& Clark, R. E. (2006). Setting the scene: Complexity and learning environments. In J. Elen, \& R. Clark (Eds.), Handling complexity in learning environments: Theory and research. Advances in Learning and Instruction (pp. 1-11). Amsterdam: Elsevier.

Elen, J., Lowyck, J., \& Proost, K. (1996). Design of telematic learning environments: A cognitive mediational view. Educational Research and Evaluation, 2(3), 213-230. http://dx.doi.org/10.1080/1380361960020301

Elliot, A. J., \& Church, M. A. (1997). A hierarchical model of approach and avoidance achievement motivation. Journal of Personality and Social Psychology, $218-232$. http://dx.doi.org/10.1037/0022-3514.72.1.218

Elliot, A. J., \& McGregor, H. A. (2001). A 2 x 2 achievement goal framework. Journal of Personality and Social Psychology, 80(3), 501-519. http://dx.doi.org/10.1037//0022-3514.80.3.501

Gerjets, P. H., \& Hesse, F. W. (2004). When are powerful learning environments effective? The role of learner activities and of students' conceptions of educational technology. International Journal of Educational Research, 41(6), 445-465. http://dx.doi.org/10.1016/j.ijer.2005.08.011

Greene, B. A., \& Land, S. M. (2000). A qualitative analysis of scaffolding use in a resource-based learning environment involving the World Wide Web. Journal of Educational Computing Research, 23(2), 151-179. http://dx.doi.org/10.2190/1GUB-8UE9-NW80-CQAD

Greene, J. A., \& Azevedo, R. (2007). Adolescents' use of self-regulatory processes and their relation to qualitative mental model shifts while using hypermedia. Journal of Educational Computing Research, 36(2), 125-148. http://dx.doi.org/10.2190/G7M1-2734-3JRR-8033

Hartley, K., \& Bendixen, L. D. (2001). Educational research in the internet age: Examining the role of individual characteristics. Educational Researcher, 30(9), 22-26. http://dx.doi.org/10.3102/0013189x030009022

Huet, N., Escribe, C., Dupeyrat, C., \& Sakdavong, J.-C. (2011). The influence of achievement goals and perceptions of online help on its actual use in an interactive learning environment. Computers in Human Behavior, 27(1), 413-420. http://dx.doi.org/10.1016/j.chb.2010.09.003

Iiyoshi, T., \& Hannafin, M. J. (1998, April). Cognitive tools for open-ended learning environments: Theoretical and implementation perspectives. Paper presented at the annual meeting of the American Educational Research Association, San Diego, CA, USA. 
Jiang, L., \& Elen, J. (2010). The impact of motivation-related variables on scaffold use. EARLI SIG 6\&7: Instructional design for motivated and competent learning in a digital world.

Jiang, L., \& Elen, J. (2011). Instructional effectiveness of higher-order questions: The devil is in the detail of students' use of questions. Learning Environments Research, 14(3), 279-298. http://dx.doi.org/10.1007/s10984-011-9095-x

Juarez-Collazo, N. A., Elen, J., \& Clarebout, G. (2012). Perceptions for Tool Use: In Search of a Tool Use Model. World Conference on Educational Multimedia, Hypermedia and Telecommunications (Ed-Media 2012), 2905-2912.

Juarez-Collazo, N. A., Lust, G., Elen, J., \& Clarebout, G. (2011). Tool use in a psychomotor task: The role of tool and learner variables. International Journal of Instruction, 4(2), 139-160.

Lajoie, S. P., \& Azevedo, R. (2006). Teaching and learning in technology-rich environments. In P. Alexander, \& P. H. Winne (Eds.), Handbook of Educational Psychology. Mahwah, New Jersey: Lawrence Erlbaum Associates, Publishers.

Lawless, K. A., \& Brown, S. W. (1997). Multimedia learning environments: Issues of learner control and navigation. Instructional Science, 25(2), 117-131. http://dx.doi.org/10.1023/A:1002919531780

Lee, Y. B., \& Lehman, J. D. (1993). Instructional cuing in hypermedia: A study with active and passive learners. Journal of Educational Multimedia and Hypermedia, 2(1), 25-37.

Legris, P., Ingham, J., \& Collerette, P. (2003). Why do people use information technology? A critical review of the technology acceptance model. Information \& Management, 40(3), 191-204. http://dx.doi.org/Pii S0378-7206(01)00143-4

Lowyck, J., Elen, J., \& Clarebout, G. (2004). Instructional conceptions: Analysis from an instructional design perspective. International Journal of Educational Research, 41(6), 429-444. http://dx.doi.org/10.1016/j.jier.2005.08.010

Lust, G., Juarez-Collazo, N. A., Elen, J., \& Clarebout, G. (2012). Content management systems: Enriched learning opportunities for all? Computers in Human Behavior, 28(3), 795-808. http://dx.doi.org/10.1016/j.chb.2011.12.009

Martens, R. L., Poelmans, P. H. A. G., Daal, M. M., \& Valcke, M. M. A. (1993). Varying embedded support devices in a course: What is the effect? (OTIC Research report 44, Ed., p. 28). Heerlen, the Netherlands: Open University, Centre for Educational Technology and Innovation.

Martens, R. L., Valcke, M. M. A., \& Portier, S. J. (1997). Interactive learning environments to support independent learning: The impact of discernability of embedded support devices. Computers \& Education, 28(3), 185-197. http://dx.doi.org/10.1016/S0360-1315(97)84657-X

Merrill, M. D. (1980). Learner control in computer based learning. Computers and Education, 4(2), 77-95. http://dx.doi.org/10.1016/0360-1315(80)90010-x

Merrill, M. D. (1983). Component display theory. In C. M. Reigeluth (Ed.), Instructional Design Theories and Models: An overview of their current status. Hillsdale, NJ: Erlbaum Associates.

Murphy, P. K., \& Alexander, P. A. (2000). A Motivated Exploration of Motivation Terminology. Contemporary Educational Psychology, 25(1), 3-53. http://dx.doi.org/10.1006/ceps.1999.1019

Newman, R. E. (1994). Adaptive help-seeking: A strategy of self-regulated learning. In D. H. Schunk, \& B. J. Zimmerman (Eds.), Self-regulation of learning and performance. Issues and educational applications. Hillsdale, New Jersey: Lawrence Erlbaum Associates.

Novak, J., \& Cañas, A. (2008). The theory underlying concept maps and how to construct and use them. Technical Report IHMC CmapTools 2006-01 Rev 01-2008. Retrieved from http://cmap.ihmc.us/Publications/ResearchPapers/TheoryUnderlyingConceptMapsHQ.pdf

Novak, J., \& Gowin, D. B. (1984). Learning how to learn. New York: Cambridge University Press. http://dx.doi.org/10.1017/CBO9781139173469

Perkins, D. N. (1985). The fingertip effect: How information-processing technology shapes thinking. Educational Researcher, 14(7), 11-17. http://dx.doi.org/10.3102/0013189X014007011

Pintrich, P. R., Smith, D. A. F., Garcia, T., \& McKeachie, W. J. (1991). A manual for the use of the Motivated Strategies for Learning Questionnaire (MSLQ). Ann Arbor, MI: National Center for Research to Improve 
Postsecondary Teaching and Learning (NCRIPTAL), University of Michigan.

Pressley, M., Snyder, B. L., Levin, J. R., Murray, H. G., \& Ghatala, E. S. (1987). Perceived Readiness for Examination Performance (PREP) produced by initial reading of text and text containing adjunct questions. Reading Research Quarterly, 22(2), 219-236. http://dx.doi.org/10.2307/747666

Raes, D., Geerts, S., \& Vanuytrecht, E. (2009). Waarom water broodnodig is. Bio-Ingenieus, 12(5), 2-4.

Rodriguez, A. J. (2006). Using concept maps as a tool for curriculum plannig and assessment in culturally diverse schools. Paper presented at the Second International Conference on Concept Mapping, San Jose, Costa Rica.

Rogers, C. R., \& Freiberg, H. J. (1994). Freedom to Learn (3rd ed.). Columbus, OH: Merrill/Macmillan.

Ruiz-Primo, M. A. (2004). Examining concept maps as an assessment tool. Paper presented at the First International Conference on Concept Mapping, Pamplona, Spain.

Schnotz, W., \& Heiss, A. (2009). Semantic scaffolds in hypermedia learning environments. Computers in Human Behavior, 25(2), 371-380. http://dx.doi.org/10.1016/j.chb.2008.12.016

Viau, R., \& Larivée, J. (1993). Learning Tools with Hypertext: An experiment. Computers \& Education, 20(1), 11-16. http://dx.doi.org/10.1016/0360-1315(93)90066-R

Wild, K.-P., \& Schiefele, U. (1994). Lernstrategien im studium. Ergebnisse zur faktorenstruktur und reliabilität eines neuen fragebogens [Learning strategies in academic studies. Results about factor structure and reliability of a new questionnaire]. Zeitschrift für Differentielle und Diagnostische Psychologie, 15, 185-200.

Winne, P. H. (1985). Steps toward promoting cognitive achievements. The Elementary School Journal, 85(5), 673-693. http://dx.doi.org/10.1086/461429

Wu, X., Lowyck, J., Sercu, L., \& Elen, J. (2011). Task complexity, student perceptions of vocabulary learning in EFL, and task performance. British Journal of Educational Psychology, in press. http://dx.doi.org/10.1111/j.2044-8279.2011.02061.x

Zeilik, M., Schau, C., Mattern, N., Hall, S., Teague, K. W., \& Bisard, W. (1997). Conceptual astronomy: A novel model for teaching postsecondary science courses American Journal of Physics, 65(10), 987-996. http://dx.doi.org/10.1119/1.18702

Zimmerman, B. J. (2000). Attaining self-regulation: A social cognitive perspective. In M. Boekaerts, P. R. Pintrich, \& M. Zeidner (Eds.), Handbook of self-regulation (pp. 13-40). http://dx.doi.org/10.1016/B978-012109890-2/50031-7

Zumbach, J. (2009). The role of graphical and text based argumentation tools in hypermedia learning. Computers in Human Behavior, 25(4), 811-817. http://dx.doi.org/10.1016/j.chb.2008.07.005

\section{Copyrights}

Copyright for this article is retained by the author(s), with first publication rights granted to the journal.

This is an open-access article distributed under the terms and conditions of the Creative Commons Attribution license (http://creativecommons.org/licenses/by/3.0/). 